\title{
Worldwide Original Research Production on Maternal Near-Miss: A 10-year Bibliometric Study
}

\author{
Akram Hernández-Vásquez ${ }^{1}$ (1) \\ Guido Bendezu-Quispe ${ }^{20}$ \\ Oswaldo Gonzales-Carillo4이 \\ 1 Universidad San Ignacio de Loyola, Vicerrectorado de Investigación, \\ Centro de Excelencia en Investigaciones Económicas y Sociales en \\ Salud, Lima, Perú \\ 2 Universidad San Ignacio de Loyola, Vicerrectorado de Investigación, \\ Unidad de Investigación para la Generación y Síntesis de Evidencias \\ en Salud. Lima, Perú \\ 3 Instituto de Efectividad Clínica y Sanitaria, Buenos Aires, Argentina \\ ${ }^{4}$ Instituto Nacional Materno Perinatal, Lima, Perú
}

Daniel Comandé3®i

Address for correspondence Guido Bendezu-Quispe, MD, MS, Unidad de Investigación para la Generación y Síntesis de Evidencias en Salud, Vicerrectorado de Investigación, Universidad San Ignacio de Loyola, Avenida La Fontana 550, La Molina, 15024, Peru

(e-mail: gbendezu@usil.edu.pe).

Rev Bras Ginecol Obstet 2020;42(10):614-620.

\begin{abstract}
Objective To evaluate the global productivity regarding original articles on maternal near-miss (MNM).

Methods We conducted a bibliometric analysis of original articles published from 2008 to November 2019 in the journals indexed in the Scopus database. The averages of the number of articles by author, of the number of authors by article, of the number of citations by article, and the total number of documents with one or more authors were obtained. An analysis of the co-citation of authors and a co-occurrence analysis of the terms included in the titles and abstracts were performed and were presented as network visualization maps.

Results A total of 326 original articles were analyzed. There was an increase in the number of articles ( $p<0.001$; average annual growth rate $=12.54 \%$ ). A total of 1,399 authors, an average number of articles per author of 4.29 , with an index of authors per document of 0.23 , and an index of co-authors per document of 8.16 were identified. A total of 85 countries contributed with original articles on MNM. Among the top ten countries regarding the contribution of articles, five were low and middle-income countries (LMICs). Brazil had the highest volume of production (31.1\%), followed by the

\section{Keywords}

- near-miss

- healthcare

- maternal health

- maternal health services US (11.5\%). Terms related to countries and the measurement of the rates and cases of MNM and the associated factors were found in recent years in the analysis of the cooccurrence of terms.

Conclusion There was an increase in the production of original articles on MNM, with a significant participation of authors and institutions from LMICs, which reveals a growing interest in the use of MNM indicators to improve the quality of maternal health care.
\end{abstract}

received

January 26, 2020

accepted

June 25,2020
DOI https://doi.org/

$10.1055 / \mathrm{s}-0040-1715136$. ISSN 0100-7203.
Copyright $\odot 2020$ by Thieme Revinter

Publicações Ltda, Rio de Janeiro, Brazil
License terms

(c) (i) 


\section{Introduction}

Maternal mortality is the indicator traditionally used to assess the quality of maternal health services and health systems. ${ }^{1,2}$ However, maternal deaths represent only the "tip of the iceberg" of maternal health problems, and for every woman who dies from causes related to pregnancy, another 20 or 30 experience acute or chronic morbidity. ${ }^{3,4}$

Currently, the measurement of the rate of maternal nearmiss (MNM) as an indicator of the evaluation of maternal health is being promoted. ${ }^{5}$ MNM is a term that describes the case of a woman who presented a medical condition related to a potentially-fatal pregnancy but survived. There are several definitions and criteria to determine a case of MNM. ${ }^{5}$ Therefore, the World Health Organization (WHO) in 2008, established a definition for MNM: a complication that occurred during pregnancy, childbirth or within 42 days of the termination of pregnancy; it also established criteria for the determination of cases of MNM and championed surveillance of the cases of MNM for the improvement of the quality of health systems. ${ }^{5,6}$

The concept of MNM has been attracting growing interest in the scientific community as a benchmark indicator to evaluate the results in maternal health of the population, with advantages over the evaluation from mortality. The study of women who survived a life-threatening complication enables the identification of the shortcomings and successes regarding assistance, and it also enables physicians to deepen the understanding of the disease process from the perspective of the patients, situations that are not possible in cases of maternal death. ${ }^{7-9}$ Since the last decade, several studies have been using bibliometric methods to evaluate scientific productivity in several biomedical fields. ${ }^{8,9}$ Although the measurement of the rate of MNM is promoted as an indicator of the quality of maternal health care, ${ }^{6,10}$ in the scientific literature there is a lack of studies that estimate the global production of research on MNM.

The present bibliometric analysis sought to assess the global productivity of original articles on MNM, including the quantity, quality, and an analysis of the citations by authors and of the co-occurrence of terms in documents, to determine if there has been an increase in the scientific production and what are the characteristics of the original articles published on MNM after the promotion of its use for the evaluation and improvement of maternal health.

\section{Methods}

\section{Study Design}

We conducted a bibliometric analysis of original articles published from 2008 (the year in which the definition and criteria of MNM proposed by the WHO were made available) to November 2019 in journals indexed in the Scopus (https://www.scopus.com/) database. While this database of bibliographic citations includes various types of documents, only original articles were included in the present analysis.

\section{Data Source}

Scopus is the largest database of citations and abstracts of peer-reviewed scientific literature to date, including more than 24 thousand titles from more than 11 thousand publishers. ${ }^{11}$ Scopus was used as a source of information since it includes all MEDLINE documents (the most widely-used free-access citation database), and includes additional features about the authors and the citations per document, which are useful for the quality and quantity measurements proposed for the present study. ${ }^{11}$

\section{Search Strategy}

The search strategy was developed by a librarian (DC), dated between January 1, 2008, and November 30, 2019, including free terms to be searched in the title, summary, and keywords of the documents indexed in Scopus. The search strategy used was as follows: ((KEY (mothers)) OR (TITLE-ABS-KEY (maternal)) OR(TITLE-ABS-KEY (mother*)) OR(TITLE-ABS-KEY (pregnan $\left.^{*}\right)$ ) OR (TITLE-ABS-KEY (obstetric $\left.\left.{ }^{*}\right)\right)$ ) AND ((TITLE-ABS-KEY (“Near-Miss”)) OR (TITLE-ABS-KEY (“Near-Misses”)) OR (TITLE-ABS-KEY ("Life-Threatening"))). The validity of the search strategy was tested through a manual review of the retrieved articles by an author (GBQ) independently.

Table 1 Number of publications on maternal near-miss by year and top ten authors

\begin{tabular}{|c|c|c|}
\hline Characteristics & Number of articles & $\%$ of articles \\
\hline \multicolumn{3}{|l|}{ Year } \\
\hline 2008 & 9 & $2.76 \%$ \\
\hline 2009 & 16 & $4.91 \%$ \\
\hline 2010 & 17 & $5.21 \%$ \\
\hline 2011 & 15 & $4.60 \%$ \\
\hline 2012 & 16 & $4.91 \%$ \\
\hline 2013 & 21 & $6.44 \%$ \\
\hline 2014 & 37 & $11.35 \%$ \\
\hline 2015 & 36 & $11.04 \%$ \\
\hline 2016 & 42 & $12.88 \%$ \\
\hline 2017 & 45 & $13.80 \%$ \\
\hline 2018 & 39 & $11.96 \%$ \\
\hline 2019 & 33 & $10.12 \%$ \\
\hline \multicolumn{3}{|l|}{ Author } \\
\hline Cecatti JG & 53 & $16.26 \%$ \\
\hline Souza JP & 37 & $11.35 \%$ \\
\hline Parpinelli MA & 33 & $10.12 \%$ \\
\hline Sousa $\mathrm{MH}$ & 32 & $9.82 \%$ \\
\hline Costa ML & 31 & $9.51 \%$ \\
\hline Haddad SM & 24 & $7.36 \%$ \\
\hline Pacagnella RC & 23 & $7.06 \%$ \\
\hline Surita FG & 22 & $6.75 \%$ \\
\hline Say L & 18 & $5.52 \%$ \\
\hline Pattinson RC & 16 & $4.91 \%$ \\
\hline
\end{tabular}




\section{Data Collection}

The complete records of each publication retrieved in the search were downloaded as a .csv file from Scopus and imported into the Rayyan (https://rayyan.qcri.org) web application, in which an author (GBQ) selected, by title and summary, the articles that met the inclusion criteria (having been published since 2008, and presenting results on MNM or MNM rates).

Only original articles published since 2008 were included because this was the year the definition and criteria proposed by the WHO for the definition of cases of MNM were published. ${ }^{5,6}$

\section{Bibliometric Analysis}

The Bibliometrix R-tool (http://www.bibliometrix.org/) was used for the bibliometric analysis. Since documents with erroneous attributions in the author's name and affiliation domains were detected, a standardization was performed manually by one of the authors (AHV). The characteristics of the documents analyzed were described, including the average of articles by author, the average of authors per article, the average of citations per article, and the number of documents with one or more authors. Additionally, some useful rates for the bibliometric evaluation were described, such as the rate of authors per article (ratio between the total number of articles and the total number of authors), the rate of co-authors per article (average number of co-authors per article) and the ratio of collaboration (ratio between the total number of authors of articles with several authors and the total of articles with several authors). More information about the calculation and how these bibliometric rates are obtained can be reviewed on the Bibliometrix website. ${ }^{12}$

The VOSviewer (Leiden University, Leiden, The Netherlands) software was used to build and visualize bibliometric networks based on analyses of bibliographic couplings, co-authorships, and co-citations, using information about the authors, journals, institutions and countries associated with the publications. A threshold was established for the cooccurrence of terms in titles and summaries of five mentions (the terms human, health, women's health, mnm, and article were excluded).

\section{Results}

The results of 326 original articles published between January 2008 and November 2019 (-Table 1) were analyzed. During the study period, there was an increase in the number of original articles on MNM $\left(p<0.001 ; \mathrm{R}^{2}=0.77\right)$, with an average annual growth rate of $12.54 \%$.

A total of 1,399 authors were identified with 2,660 occurrences. Only four original articles had a single author. An average of the number of articles per author of 4.29 was found,

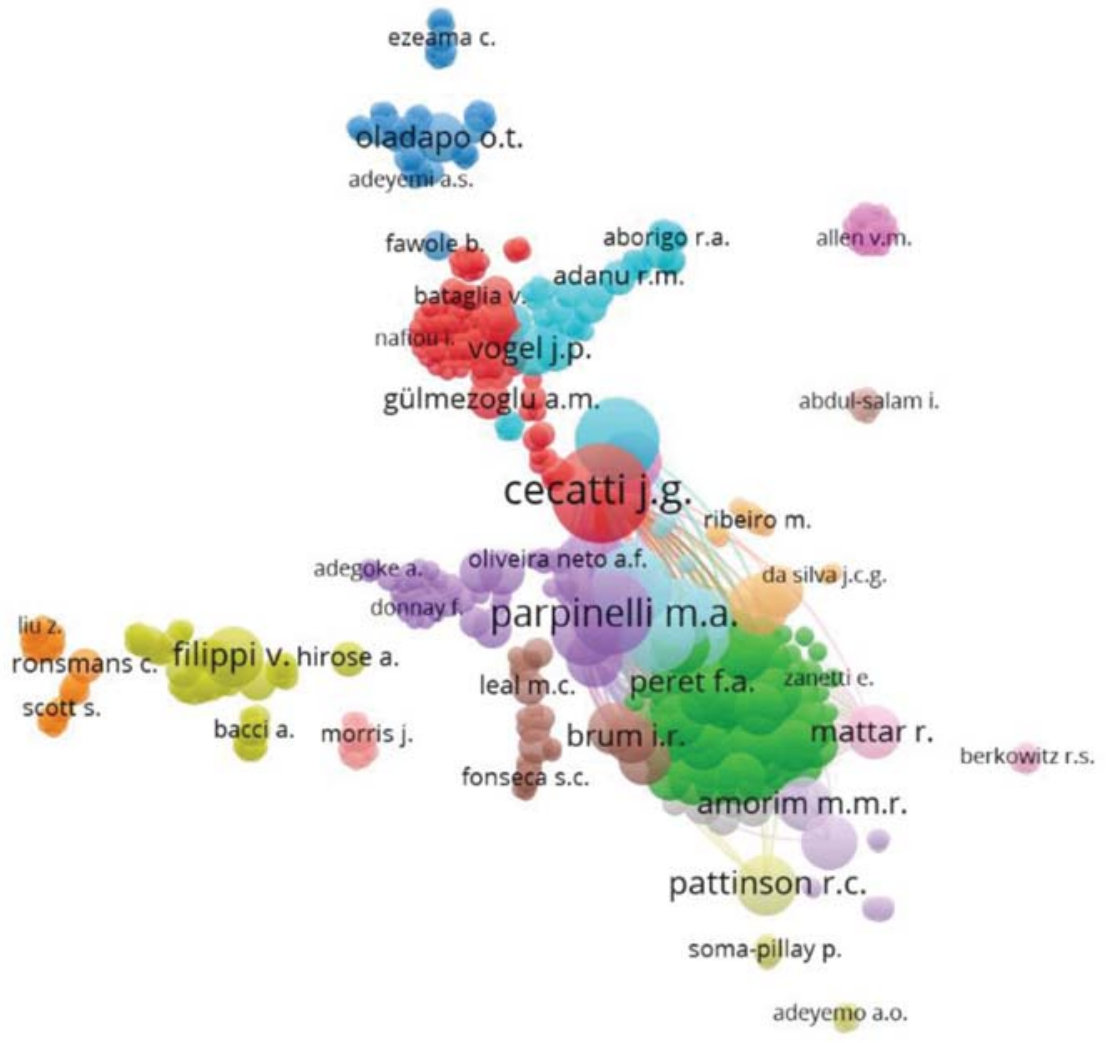

\section{VOSviewer}

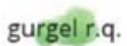

Fig. 1 Analysis of co-authorship with the VOSviewer software regarding publications on maternal near-miss. 
Table 2 Top ten countries with more publications on maternal near-miss, and some citation indices

\begin{tabular}{lllllll}
\hline Rank & Country & $\begin{array}{l}\text { Number of } \\
\text { articles }\end{array}$ & $\begin{array}{l}\text { \% of } \\
\text { articles }\end{array}$ & $\begin{array}{l}\text { Single-country } \\
\text { publications }\end{array}$ & $\begin{array}{l}\text { Multiple-country } \\
\text { publications }\end{array}$ & $\begin{array}{l}\text { Multiple-country } \\
\text { publication ratio }\end{array}$ \\
\hline 1 & Brazil & 65 & 31.1 & 54 & 11 & 0.17 \\
2 & USA & 24 & 11.48 & 13 & 11 & 0.46 \\
3 & India & 18 & 8.61 & 17 & 1 & 0.06 \\
4 & United Kingdom & 18 & 8.61 & 9 & 9 & 0.5 \\
5 & Uganda & 6 & 2.87 & 6 & 0 & 0 \\
6 & China & 5 & 2.39 & 4 & 1 & 0.2 \\
7 & Canada & 4 & 1.91 & 1 & 3 & 0.75 \\
8 & Nigeria & 4 & 1.91 & 4 & 0 & 0 \\
9 & Pakistan & 4 & 1.91 & 4 & 0 & 0 \\
10 & Sweden & 4 & 1.91 & 1 & 3 & 0.75 \\
\hline
\end{tabular}

with an index of authors per document of 0.23 , and an index of co-authors per document of 8.16. The rate of collaborations was of 4.33. Ceccatti JG (53 documents) and Souza JP (37 documents) were the authors with the highest number of publications (- Table 1). Among the top ten authors with the highest volume of production of original articles, eight were affiliated with an institution in Brazil. In - Fig. 1, a co-authorship analysis is presented, including authors with more than five original articles, with each circle representing an author. The size of the circle indicates the volume of the productivity (the larger the circle, the greater the number of author's documents) and the proximity of the circles indicates a close collaboration. As a result, the formation of collaborative networks around the aforementioned authors with a greater volume of scientific production is evident.

A total of 85 countries contributed with original articles on MNM. According to the country of origin of the institutional affiliation of the authors of the original articles on MNM, Brazil had the highest proportion of publications (31.1\%), followed by the US (11.5\%). Among the top ten countries regarding the contribution of original articles on
MNM, five were low and middle-income countries (LMICs) according to the 2019 World Bank classification. Similarly, the countries of origin of the institutions of the most frequent correspondent authors were Brazil and the US (65 and 24 documents respectively) and they presented the largest number of collaborative documents with institutional affiliations from different countries ( 11 for each country). Brazil presented the largest number of documents as the only country of the institutional affiliations of the authors: 54) (-Table 2).

Regarding the citations, the original articles had an average of 13.47 citations. The articles by Say L et $\mathrm{al}^{5}$ (2009) and Souza JP et $\mathrm{al}^{13}$ (2014) presented the highest number of citations (391 and 300, with a citation average of 35.55 and 42.86 per year respectively). On the scientific journals, BMC Pregnancy and Childbirth published the largest number of MNM publications (44; $13.50 \%)$, followed by the International Journal of Gynecology and Obstetrics (23; 7.06\%) (-Table 3).

In the co-occurrence analysis of terms ( - Fig. 2), the terms: prospective surveillance, score, main outcome measure, mortality ratio, case fatality rate, delayed mortality, association,

Table 3 Top ten journals publishing original articles on maternal near-miss

\begin{tabular}{llll}
\hline Journal & Number of articles & \% of articles & 2018 h-index $^{*}$ \\
\hline BMC Pregnancy and Childbirth & 44 & $13.50 \%$ & 66 \\
International Journal of Gynecology and Obstetrics & 23 & $7.06 \%$ & 88 \\
BJOG: An International Journal of Obstetrics and Gynecology & 20 & $6.13 \%$ & 148 \\
PLOS ONE & 16 & $4.91 \%$ & 268 \\
Reproductive Health & 13 & $3.99 \%$ & 41 \\
Journal of Obstetrics and Gynecology of India & 11 & $3.37 \%$ & 12 \\
Acta Obstetricia et Gynecologica Scandinavica & 7 & $2.15 \%$ & 93 \\
Biomed Research International & 6 & $1.84 \%$ & 94 \\
Revista Brasileira de Ginecologia e Obstetrícia & 5 & $1.53 \%$ & 19 \\
Tropical Medicine And International Health & 5 & $1.53 \%$ & 101 \\
\hline
\end{tabular}

Note: ${ }^{*}$ The $h$-index is an index that attempts to measure both the productivity and impact of the published work of a scientist or scholar. 


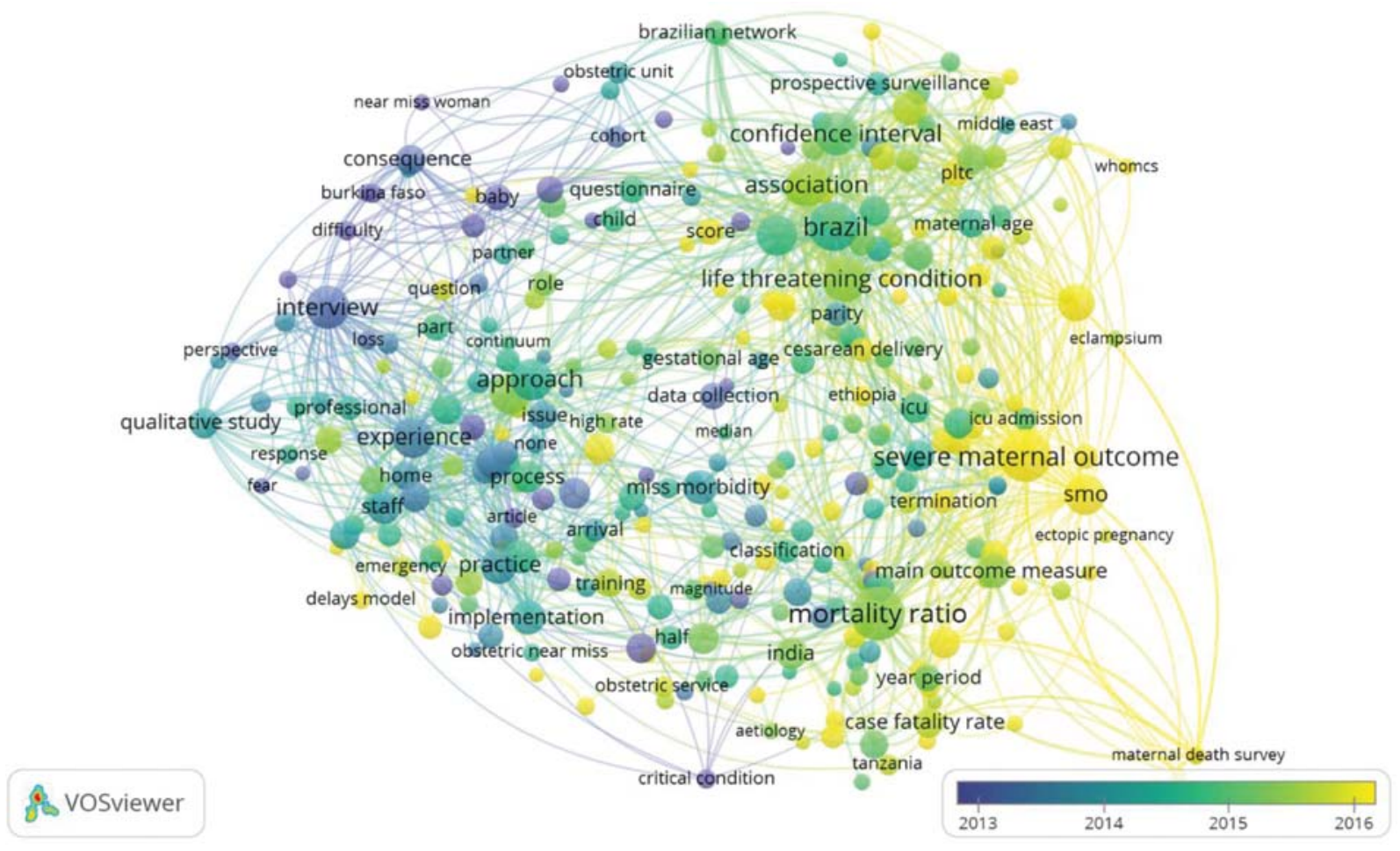

Fig. 2 Analysis of the co-occurrence of terms in titles and abstracts (overlay visualization) and their temporal evolution with the VOSviewer software regarding publications on maternal near-miss.

training, maternal death survey, severe maternal outcomes (smo), cesarean, preeclampsia, potentially life-threatening condition (pltc), as well as terms about countries such as Brazil, Ethiopia, India, and Tanzania, were found for recent years.

\section{Discussion}

The present study aimed to determine the production and characteristics of the original articles on MNM published since the WHO defined the concept and criteria to measure the cases and rates of MNM. As a result, an increase in the production of original articles on MNM was found during the last decade. Almost a third of the scientific production on MNM is from Brazil, the country of origin of the institutional affiliations of the most productive authors. Additionally, half of the countries in the top ten with the highest volume of production on MNM are LMICs, with the other half composed of high-income countries, such as the US and the United Kingdom. The analysis of the co-occurrence of terms indicated that in recent years the cases and rates of MNM and its associated factors have been measured in various countries, in addition to the study of health systems around MNM. These results indicated that the scientific production on MNM has been increasing, it comes mostly from LMICs, and has been presenting a tendency to study associations or to report experiences of measuring the rates and cases of MNM in various health systems.

During the study period, an increase in the number of original articles on MNM is evidenced. International initiatives have been promoting an improvement in maternal health indicators, such as the United Nations Sustainable
Development Goals (SDG), which propose a reduction by 2030 in the global maternal mortality rate to $<70$ per 100,000 live births and the provision of universal access to sexual and reproductive health care services and the integration of reproductive health in national strategies and programs. ${ }^{2}$ Thus, an international context of improvement of maternal and child care could be a promoter of a greater scientific production on MNM, having been described through other bibliometric studies, the increase of the scientific production in obstetrics in the. ${ }^{14,15}$ Given the priority that exists in the evaluation of health systems for the improvement of maternal health and the consequent reduction in mortality, ${ }^{13}$ the increase in the production of original articles on MNM reveals a scenario in which the measurements are increasing on maternal health care, which can provide useful information for the improvement of health systems.

Among the top ten countries regarding the production of original articles on MNM, five (Brazil, India, Uganda, Nigeria, and Pakistan) are classified as LMICs by the World Bank, ${ }^{16}$ with Brazil being the country that leads this ranking. Countries such as the US and the United Kingdom, which occupied the second and fourth places regarding the volume of scientific production on MNM, usually lead the rankings of scientific production, including in the area of health, and the field of obstetrics is not an exception. ${ }^{14}$ Given that maternal mortality in LMICs is higher compared with that of highincome countries, ${ }^{17,18}$ one would expect that high-income countries would be in the top ten regarding the scientific production on MNM (because in countries with low rates of maternal death, the measurement of the cases and rates of 
MNM is useful to identify a greater number of cases for the audit of the care provided in establishments with maternal functions compared with the traditional systems of surveillance of maternal mortality). The fact that Brazil is the country with the highest volume of scientific production, even greater than that of high-income countries, corresponds to what was found for the MNM collaboration networks:these networks are led by researchers affiliated to Brazilian institutions, and almost all top ten authors with more articles on MNM are affiliated to Brazilian institutions. These results suggest that countries with different levels of income have been measuring MNM for the improvement of the maternal health of their populations, which determines an opportunity for the health systems to be able to have more data for the analysis and improvement of their attention processes at the local level.

In the analysis of the co-occurrence of terms, we found that, in recent years, terms such as maternal death survey, delayed model, obstetric service and score reflect that MNM has been evaluated from the perspective of maternal health services. The use of standards for maternal health care, including electronic or non-registration, surveillance, and response systems on maternal care data has been described to improve decision-making. ${ }^{19,20}$ Since the measurement of the rates and cases of MNM contributes to the audit of the quality of maternal health care, these results would reflect the interest in the evaluation or development of maternal health surveillance systems worldwide, which corresponds to some articles found on MNM published over the previous years. Other terms reported in more recent studies, such as cesarean section, preeclampsia, severe maternal outcome (smo), termination, case fatality rate, association and potentially life-threatening condition (pltc), as wellas terms that describe countries such as Brazil, Ethiopia, India, and Tanzania reflect that, in recent years, the authors have been conducting studies that measure the cases and rates of MNM according to specific maternal health conditions and their associated factors, ${ }^{21-25}$ or studies for the validation of the MNM criteria in these countries. ${ }^{26-29}$

Terms related to severe acute maternal morbidity were not included, since this is a term interchangeable with MNM, and the WHO does not recommend refering to severe, life-threatening obstetric complications. Similarly, since we did not include articles that did not have MNM as the main subject mentioned in the title, abstract or keywords, it is possible that some studies that evaluated MNM but did not include this information in these fields may have been excluded. Hence, considering that studying MNM is in line with the proposed goals for the improvement of maternal health indicators as part of the SDGs, despite the limitations of the present study, we consider adequate the use of the year 2008 as a point of review about the status of MNM publications to evaluate the worldwide research production of studies on MNM. Furthermore, the search strategy used in the present study was developed by a librarian with extensive experience in developing search strategies in the field of health to ensure the quality of this procedure.

\section{Conclusion}

In conclusion, there was a sustained increase in the scientific production of articles on MNM since 2008, with an important participation of authors and institutions from LMICs. Brazil is the leading country in terms of scientific production and collaborative networks. The current publications on MNM aim to measure the associations or results of surveillance systems or to validate the criteria to measure the rates and cases of MNM at the local level for the improvement of maternal health. Given the benefits of the measurement of maternal health indicators from the perspective of MNM compared with the traditional measurements or health surveillance of maternal mortality, the increase in the scientific production of articles in recent years on the evaluation of systems of surveillance of MNM reveals an interest in improving the quality of maternal health care from a different perspective, and that should favor clinical decisionmaking and planning at the level of the health system.

\section{Ethical Considerations}

The present study did not require the approval of an ethics committee since the data obtained from Scopus represents secondary data that does not include sensitive information.

\section{Contributors}

All of the authors made substantial contributions to the manuscript, and met the ICMJE authorship criteria.

\section{Conflict of Interests}

The authors have no conflict of interest to declare.

\section{References}

1 Ronsmans C, Graham WJ; Lancet Maternal Survival Series steering group. Maternal mortality: who, when, where, and why. Lancet. 2006;368(9542):1189-1200. Doi: 10.1016/S0140-6736(06)69380-X

2 United Nations. Sustainable Development Goals. Goal 3: Ensure healthy lives and promote well-being for all at all ages [Internet]. 2020 [cited 2020 Jan 10]. Available from: https://www.un.org/sustainabledevelopment/health/

3 Reichenheim ME, Zylbersztajn F, Moraes CL, Lobato G. Severe acute obstetric morbidity (near-miss): a review of the relative use of its diagnostic indicators. Arch Gynecol Obstet. 2009;280(03): 337-343. Doi: 10.1007/s00404-008-0891-1

4 Nanda G, Switlick K, Lule E. Accelerating progress towards achieving the MDG to improve maternal health: a collection of promising approaches [Internet]. Washington (DC): World Bank; 2005 [cited 2019 Dec 11]. Available from: http://documents.worldbank.org/curated/en/939471468163156282/pdf/319690HNP0Nand1ingProgress01public1.pdf

5 Say L, Souza JP, Pattinson RC; WHO working group on Maternal Mortality and Morbidity classifications. Maternal near misstowards a standard tool for monitoring quality of maternal health care. Best Pract Res Clin Obstet Gynaecol. 2009;23(03):287-296. Doi: 10.1016/j.bpobgyn.2009.01.007

6 World Health Organization. Department of Reproductive Health and Research. Evaluating the quality of care for severe pregnancy complications: the WHO near-miss approach for maternal health [Internet]. Geneva: WHO; 2011 [cited 2019 Dec 11]. Available from: https://apps.who.int/iris/bitstream/handle/10665/44692/ 9789241502221_eng.pdf?sequence $=1$ 
7 Lazzerini M, Richardson S, Ciardelli V, Erenbourg A. Effectiveness of the facility-based maternal near-miss case reviews in improving maternal and newborn quality of care in low-income and middle-income countries: a systematic review. BMJ Open. 2018;8 (04):e019787. Doi: 10.1136/bmjopen-2017-019787

8 Cheng T, Zhang G. Worldwide research productivity in the field of rheumatology from 1996 to 2010: a bibliometric analysis. Rheumatology (Oxford). 2013;52(09):1630-1634. Doi: 10.1093/rheumatology/ket008

9 England N, Madill J, Metcalfe A, Magee L, Cooper S, Salmon C, et al. Monitoring maternal near miss/severe maternal morbidity: a systematic review. ssrn:3444404 [Preprint] 2019. Doi: 10.2139/ssrn.3444404

10 Lewis G. Emerging lessons from the FIGO LOGIC initiative on maternal death and near-miss reviews. Int J Gynaecol Obstet. 2014;127(Suppl 1):S17-S20. Doi: 10.1016/j.ijgo.2014.07.007

11 Scopus. Data | Curated. Connected. Complete [Internet]. 2019 [cited 2019 Dec 12]. Available from: https://www.elsevier.com/_data/ assets/pdf_file/0017/114533/Scopus_GlobalResearch_Factsheet2019 _FINAL_WEB.pdf

12 Aria M, Cuccurullo C. A brief introduction to bibliometrix [Internet]. 2020 [cited 2020 Jan 10]. Available from: https://cran.r-project.org/ web/packages/bibliometrix/vignettes/bibliometrix-vignette.html

13 Souza JP, Widmer M, Gülmezoglu AM, Lawrie TA, Adejuyigbe EA, Carroli G, et al. Maternal and perinatal health research priorities beyond 2015: an international survey and prioritization exercise. Reprod Health. 2014;11:61. Doi: 10.1186/1742-4755-11-61

14 Palacios-Marqués AM, Carratala-Munuera C, Martínez-Escoriza JC, et al. Worldwide scientific production in obstetrics: a bibliometric analysis. Ir J Med Sci.. 2019;188(03):913-919. Doi: 10.1007/s11845-018-1954-3

15 Souza JP, Widmer M, Gülmezoglu AM, Lawrie TA, Adejuyigbe EA, Carroli G, et al. Maternal and perinatal health research priorities beyond 2015: an international survey and prioritization exercise. Reprod Health. 2014;11:61. Doi: 10.1186/1742-4755-11-61

16 The World Bank. Data: World Bank Country and Lending Groups [Internet]. 2020 [cited 2020 Mar 10]. Available from: https:// datahelpdesk.worldbank.org/knowledgebase/articles/906519world-bank-country-and-lending-groups

17 World Health Organization. Maternal, newborn, child and adolescent health: what is quality of care and why is it important? [Internet]. 2020 [cited 2020 Mar 10]. Available from: https://www.who.int/maternal_child_adolescent/topics/quality-of-care/definition/en/

18 Alkema L, Chou D, Hogan D, Zhang S, Moller AB, Gemmill A, et al; United Nations Maternal Mortality Estimation Inter-Agency Group collaborators and technical advisory group. Global, regional, and national levels and trends in maternal mortality between 1990 and 2015, with scenario-based projections to 2030: a systematic analysis by the UN Maternal Mortality Estimation Inter-Agency Group. Lancet. 2016;387(10017):462-474. Doi: 10.1016/s0140-6736(15)00838-7
19 World Health Organization. Standards for improving quality of maternal and newborn care in health facilities [Internet]. Geneva: WHO; 2016 [cited 2019 Nov. 25]. Available from: https://apps. who.int/iris/bitstream/handle/10665/249155/9789241511216eng.pdf? sequence $=1$

20 World Health Organization. Maternal Death Surveillance and Response - background [Internet]. Maternal, newborn, child and adolescent health. 2020 [cited 2020 Jan 12]. Available from: https://www.who.int/maternal_child_adolescent/epidemiology/ maternal-death-surveillance/background/en/

21 Kietpeerakool C, Lumbiganon P, Laopaiboon M, Rattanakanokchai S, Vogel JP, Gülmezoglu AM. Pregnancy outcomes of women with previous caesarean sections: Secondary analysis of World Health Organization Multicountry Survey on Maternal and Newborn Health. Sci Rep. 2019;9(01):9748. Doi: 10.1038/s41598-019-46153-4

22 Pandit R, Jain V, Bagga R, Sikka P. Using near miss model to evaluate the quality of maternal care at a tertiary health-care center: a prospective observational study. J Obstet Gynaecol India. 2019;69(05):405-411. Doi: 10.1007/s13224-019-01237-z

23 Moudi Z, Arabnezhad L, Ansari H, Tabatabaei SM. Severe maternal morbidity among women with a history of cesarean section at a tertiary referral teaching hospital in the southeast of Iran. Public Health. 2019;175:101-107. Doi: 10.1016/j.puhe.2019.07.016

24 Rangel-Flores YY, Hernández-Ibarra LE, Martínez-Ledezma AG, García-Rangel M. [Experiences of survivors of maternal near miss in Mexico: a qualitative study based on the three delays model]. Cad Saude Publica. 2019;35(09):e00035418. Doi: 10.1590/0102$311 \times 00035418$

25 Kasahun AW, Wako WG. Predictors of maternal near miss among women admitted in Gurage zone hospitals, South Ethiopia, 2017: a case control study. BMC Pregnancy Childbirth. 2018;18(01): 260. Doi: 10.1186/s12884-018-1903-1

26 Witteveen T, Bezstarosti H, de Koning I, Nelissen E, Bloemenkamp $\mathrm{KW}$, van Roosmalen J, et al. Validating the WHO maternal near miss tool: comparing high- and low-resource settings. BMC Pregnancy Childbirth. 2017;17(01):194. Doi: 10.1186/s12884-017-1370-0

27 Witteveen T, de Koning I, Bezstarosti H, van den Akker T, van Roosmalen J, Bloemenkamp KW. Validating the WHO maternal near miss tool in a high-income country. Acta Obstet Gynecol Scand. 2016;95(01):106-111. Doi: 10.1111/aogs.12793

28 Heemelaar S, Kabongo L, Ithindi T, Luboya C, Munetsi F, Bauer AK, et al. Measuring maternal near-miss in a middle-income country: assessing the use of WHO and sub-Saharan Africa maternal nearmiss criteria in Namibia. Glob Health Action. 2019;12(01): 1646036. Doi: 10.1080/16549716.2019.1646036

29 Oliveira-Neto AF, Parpinelli MA, Costa ML, Souza RT, Ribeiro do Valle C, Sousa MH, et al. Prediction of severe maternal outcome among pregnant and puerperal women in obstetric ICU. Crit Care Med. 2019;47(02):e136-e143. Doi: 10.1097/CCM.0000000000003549 